\title{
Is Love Status An Influencing Factor for obesity Level?
}

\author{
Mingyan Zou \\ School of Economic Mathematics Swufe, Southwestern University of Finance and Economics, \\ Chengdu 611130, China \\ 949699019@qq.com
}

Keywords: Obesity, love status, multiple linear regression.

\begin{abstract}
Limited research has been conducted to investigate mental state associated with obesity level in China, where obesity has been increasing. This study investigated association of one kind of mental state, love status, with obesity level among Chinese college students. We used BMI (body mass index $=$ weight/height2) to denote one's obesity level as the dependent variable, chose love status as the explanatory variable and chose some specific variables as control variables according to some literature. We collect we collected 177 valid questionnaire data from students in Southwestern University of Financial and Economics, China. We used multiple linear regression model to investigate association of love status with obesity level, and then adopted least squares estimation to fit the regression equation. The significance of each coefficient was tested by student's test with a $\mathrm{P}<0.1$ indicating statistical significance. The significance of the whole regression equation was tested by homogeneity test of variance and goodness of fit test. Furthermore, the significance of multicollinearity level was tested by VIF (variance inflation factor). Heteroscedasticity was tested by white test. The results indicated that all tests above were passed. In conclusion, towards college students, love status has influence on obesity level. The students who are in passionately in love have lower obesity level than that of students who are single, which can be explained by neurobiology and the logic of people's thinking. However, some limitations existed in the study such as the lack of test of endogeneity.
\end{abstract}

\section{Introduction}

With the improvement of people's living standard, the problem of obesity has become increasingly prevalent all over the world and is widely recognized as a key risk factor for a variety of health problems such as hypertension, diabetes, coronary heart disease and so on. In the World Health Organization (WHO) European Region, the prevalence of childhood and adolescent obesity has risen over the past few decades [1]. Similarly, in 2010, it was estimated that 9.9\% of Chinese school-aged children and adolescents were overweight and an additional $5.1 \%$ were obese, representing an estimated 30.43 million individuals [2]. The researches about factors related to obesity level are conducive to solving the obesity problem.

Some factors related to overweight and obesity have been well documented [3-9], including exercise time, snack intake, dietary structure, the usual drink type, the frequency of staying up late, working or studying time and so on. However, few studies about the effect of mental state like love status on obesity level have been conducted, which could hamper the development of effective obesity prevention programs.

According to neurobiology, when you are in passionately love, a variety of hormones in the human body will change differently, which possibly has effect on obesity level. Therefore, this study aimed to explore the association of love status with obesity level. Limited research has been conducted to investigate mental state associated with obesity level in China, where obesity has been increasing. This study investigated association of one kind of mental state, love status, with obesity level among Chinese college students. 


\section{Methods}

\subsection{Study Design.}

We used BMI to denote one's obesity level that is the dependent variable in our study. To analyse the association of love status with obesity, we adopted multiple linear regression. The dummy variable D1 denotes one's love status: be passionately in love $(D 1=1)$ or not $(D 1=0)$. We found evidences in some literatures which had proven the following factors in Table1 have impacts on BMI, so we chose these factors as control variables.

Table 1 The meanings of control variables

\begin{tabular}{|c|c|c|}
\hline Symbol & Variable & Details \\
\hline $\mathrm{D} 2$ & Gender & O: male 1: female \\
\hline $\mathrm{X} 3$ & Exercise time per week (measurement unit: hour) & \\
\hline $\mathrm{X} 4$ & The frequency of staying up late per week on average & \\
\hline $\mathrm{X} 5$ & The snack cost per week on average & \\
\hline D6 & The predilection for meat & $\begin{array}{l}(\mathrm{D} 6, \mathrm{D} 7)=(1,0) \text { denotes the } \\
\text { predilection for meat. } \\
(0,1) \text { denotes the }\end{array}$ \\
\hline D7 & The predilection for vegetable & $\begin{array}{c}\text { predilection for vegetable } \\
(0,0) \text { denotes no predilection for } \\
\text { either. }\end{array}$ \\
\hline D8 & The usual drink type & $\begin{array}{l}\mathrm{D} 8=0 \text { denotes pure water } \\
\mathrm{D} 8=1 \text { denotes beverage }\end{array}$ \\
\hline $\mathrm{X} 9$ & $\begin{array}{l}\text { The cost of buying fruits per week on average } \\
\text { (measurement unit: RMB yuan) }\end{array}$ & \\
\hline $\mathrm{X} 10$ & $\begin{array}{l}\text { Working or studying time per week on average } \\
\text { (measurement unit: hour) }\end{array}$ & \\
\hline
\end{tabular}

\subsection{Data Collection.}

The self-administered questionnaires including 11 questions were handed out online to the college students in Southwestern University of Financial and Economics, China. Finally we collected 177 valid questionnaires. After data processing, the data that can be used in statistical analysis are obtained.

There were 54 male students and 123 female students in the questionnaires, among which 48 students who are in passionately love, and 129 students who are not.

According to the standards set by WHO, in the questionnaires, there were 51 students whose BMI are less than 18.5 belonging to the thin group, 106 students whose BMI are from 18.5 to 22.9 belonging to the normal group and 20 students whose BMI are more than 23 belonging to the overweight group.

About exercise time, students exercise 1 to 9 hours per week. There were 28.3 percent of students who exercise for one hour a week, 13.0 percent of students who exercise for two hours a week, 19.2 percent of students who exercise for three hours a week, and 11.9 percent of students who exercise for four hours a week. The students who exercise for more than 4 hours a week are 27.7 percent. The students stay up late 1 to 7 times a week. There were 27.1 percent of students who stay up late 7 times a week. The number of students who stay up late less than 7 times is individually less than 20 percent. The snack cost of students in the questionnaires is from 0 to 500 yuan. The most students cost 100 yuan per week. There were 31.1 percent students who prefer to meat, 13.6 percent students who have the predilection for vegetables and 55.4 percent students who have no preference for either. There were 53.1 percent of students who like drinking pure water, and the others who like drinking beverage. Students in the questionnaire outcome spent 0 to 300 yuan on fruits per week. The number of students who spent 20 yuan per week is the largest. Students spent 0 to 18 hours per week on studying or working per week, among which most students spent 5 to 8 hours per week.

\subsection{Statistical Analysis.}

The multiple linear regression model is as followed: 


$$
\begin{aligned}
& Y_{i}=\beta_{0}+\beta_{1} * D_{1 i}+\beta_{2} * D_{2 i}+\beta_{3} * X_{3 i}+\beta_{4} * X_{4 i}+\beta_{5} * X_{5 \mathrm{i}}+\beta_{6} * D_{6 \mathrm{i}}+\beta_{7} * D_{7 \mathrm{i}} \\
& +\beta_{8} * D_{8 \mathrm{i}}+\beta_{9} * D_{9 \mathrm{i}}+\beta_{10} * X_{9 \mathrm{i}}+\beta_{11} * X_{11 \mathrm{i}}+\varepsilon_{\mathrm{i}}
\end{aligned}
$$

The estimation equation was fitted by least squares estimation. The significance of each coefficient is tested by student's $t$ test with a $\mathrm{P}<0.1$ indicating statistical significance. The significance of the whole regression equation is tested by homogeneity test of variance and goodness of fit test.

Multicollinearity level was tested by VIF. According to empirical judgement method, when $0<\mathrm{VIF}<10$, there is no strong multicollinearity; when $10<\mathrm{VIF}<100$, there is a strong multicollinearity; when VIF is larger than 100, there are serious multicollinearity. If there is a strong multicollinearity, there is possibility that the coefficient of D1 is very unstable which considerably affects the accuracy of analysis. If so, we would use stepwise regression method to alleviate multicollinearity but would not delete D1.

Since this is a cross-sectional survey, Heteroscedasticity is likely to exist that is likely to cause the wrong outcome about the significance of D1. Therefore, we used white test to test heteroscedasticity. If $\mathrm{P}<0.1$, we would say the model exhibits heteroscedasticity. Glejser test and weighted least squares would be utilized for solving the problem of heteroscedasticity.

\section{Results}

\subsection{Multiple Linear Regression.}

The multiple linear regression outcome by least squares estimation is in Table2.

Table 2 The outcome of multiple linear regression

\begin{tabular}{ccccc}
\hline Variable & Coefficient & Std. Error & t-Statistic & Prob. \\
\hline C & 24.012 & 0.889 & 27.015 & $<0.001$ \\
D1 & -0.608 & 0.360 & -1.690 & 0.093 \\
D2 & -2.302 & 0.376 & -6.128 & $<0.001$ \\
X3 & 0.107 & 0.069 & 1.563 & 0.120 \\
X4 & -0.055 & 0.080 & -0.690 & 0.491 \\
X5 & -0.003 & 0.003 & -0.890 & 0.375 \\
D6 & -0.302 & 0.366 & -0.827 & 0.409 \\
D7 & 0.862 & 0.488 & 1.765 & 0.079 \\
D8 & 0.125 & 0.326 & 0.385 & 0.701 \\
X9 & 0.004 & 0.006 & 0.624 & 0.533 \\
X10 & 0.003 & 0.030 & 0.106 & 0.915 \\
\hline R-squared & 0.259 & & & \\
\hline F-statistic & 5.772 & & & \\
\hline Probability(F-statistic) & $<0.001$ & &
\end{tabular}

The estimated regression equation is:

$Y=24.012-0.608 * D_{1}-2.302 * D_{2}+0.107 * X_{3}-0.055 * X_{4}-0.003 * X_{5}-$

$0.302 * D_{6}+0.862 * D_{7}+0.125 * D_{8}+0.004 * X_{9}+0.003 * X_{10}$

Because Probability $($ F-statistic $)<0.001$, The variables all together had significant impacts on BMI.

The P-values of D1, D2 and D7 were all smaller than 0.1 , so we could draw a preliminary result that D1 had significant impact on BMI. When the control variables were constant, the BMI of people being passionately is lower than that of other people by 0.608 on average.

\subsection{Multicollinearity Test.}

Multicollinearity test outcome by VIF is in Table3. 
Table 3 The VIF value of variables

\begin{tabular}{cccc}
\hline Variable & $\begin{array}{c}\text { Coefficient } \\
\text { Variance }\end{array}$ & $\begin{array}{c}\text { Uncentered } \\
\text { VIF }\end{array}$ & $\begin{array}{c}\text { Centered } \\
\text { VIF }\end{array}$ \\
\hline D1 & 0.130 & 1.422 & 1.034 \\
D2 & 0.141 & 17.570 & 1.194 \\
X3 & 0.005 & 3.555 & 1.190 \\
X4 & 0.006 & 6.380 & 1.122 \\
X5 & 0.000 & 3.480 & 1.742 \\
D6 & 0.134 & 1.680 & 1.155 \\
D7 & 0.238 & 1.306 & 1.128 \\
D8 & 0.106 & 2.011 & 1.062 \\
X9 & 0.000 & 3.231 & 1.723 \\
X10 & 0.001 & 2.710 & 1.043 \\
\hline
\end{tabular}

The VIF of all variables are in the range which indicates that there is no strong multicollinearity.

\subsection{Heteroskedasticity Test.}

White test outcome is in Table4.

Table 4 Heteroskedasticity white test outcome

\begin{tabular}{cccc}
\hline F-statistic & 1.370 & Prob. F(59,116) & 0.076 \\
\hline Obs*R-squared & 72.265 & Prob. Chi-Square(59) & 0.115 \\
\hline Scaled explained SS & 81.161 & Prob. Chi-Square(59) & 0.30 \\
\hline
\end{tabular}

Prob. Chi-Square(59) $=0.115>0.1$, so we say there is no heteroscedasticity.

\section{Summary}

In conclusion, towards college students, love status has influence on obesity level. The students who are in passionately in love have lower obesity level than that of students who are single.

This study was one of few studies conducted in China in exploring the association of mental state with obesity level. The prevalence of obesity was $11.3 \%$, which was consistent with other research in China [10].

From the results above, love status was a significant factor for obesity level. On average, the BMI of college students who are passionately in love are less than that of college students who are single by 0.608. In another word, the college students who are in passionately love are thinner than who are single.

This can be explained by neurobiology to a certain extent. The biochemical mechanism of central nervous system of love (between man and woman) mainly includes dopamine, oxytocin, vasopressin, five serotonin and other neurotransmitters. When a person is passionately in love, his or her dopamine level increases. The performance of increase in dopamine in behavior is the increased energy and the reduced need for sleep and food, the increased concentration. These phenomena possibly help losing weight. On the other hand, spouse connection can increase D1 receptor connection density. The animal that has formed a spouse connection may be less susceptible to addiction to food, thereby reducing the risk of obesity [11, 12]. From the logic of people's thinking, we can conjecture that college students who are in passionately love have bigger motivation to lose weight and keep fit to keep their own good images on their lovers.

One limitation of the study is that we did not test endogeneity. Specifically, there is possibility that students who have lower BMI are more likely to find lover, so we can't obtain the conclusion that being in passionately love is conducive to owning lower BMI. Due to the difficulty of finding instrumental variable of love status, we did not conduct endogeneity test. Therefore, we hope that this part can be conducted by other scholars. Another limitation is that the data is only from one college and the size of data is relatively small. 


\section{References}

[1]. WHO Regional Office for Europe. Do surgical interventions to treat obesity in children and adolescents have long- versus short-term advantages and are they cost-effective? In: HEN synthesis report. Denmark: World Health Organization; 2012. p. 1-2.

[2]. Burkhalter TM, Hillman CH. A narrative review of physical activity, nutrition, and obesity to cognition and scholastic performance across the human lifespan. Adv Nutr. 2011; 2:201S-6S.

[3]. Wang Lisen, Qi Guoying, Li Fengrong. Influence factors of sports statistics research [J]. the college journal of Beijing Sport University 2006, 29 (10): 1379-1380.

[4]. Pouresmali A, Semsarilar P, Mowlaie M, et al. Eating Habits, Family Flexibility and the Body Mass Index (BMI) in Gifted Students[J]. Open Journal of Medical Psychology, 2015, 4(4):116-123.

[5]. Yamei. Physical harm reasonable diet and stay healthy [J]. feet and health, 2015 (1): 40-41.

[6]. Hu Junfeng, Qin Chen, Xu Ting, et al. Investigation and analysis of the situation of College Students' non-normal time to go to bed -- Taking North Sichuan Medical College as an example of [J]. China Science \& technology, 2015 (17): 219-219.

[7]. Millar L, Rowland B, Nichols M, et al. Relationship between raised BMI and sugar sweetened beverage and high fat food consumption among children. [J]. Obesity (Silver Spring, Md.), 2014, 22(5): E96.

[8]. Nigatu Y T, Ven H A V D, Klink J J L V D, et al. Overweight, obesity and work functioning: The role of working-time arrangements[J]. Applied Ergonomics, 2015, 52:128-134.

[9]. You W, Henneberg M. Meat consumption providing a surplus energy in modern diet contributes to obesity prevalence: an ecological analysis[J]. BMC Nutrition, 2016, 2(1):1-1.

[10]. Li H. The growth status of Chinese children:trends in nutrition and development. Chin J Evid Base Pediatr. 2009; 5:405-10.

[11]. Fisher H E. The drive to love: The neural mechanism for mate selection. In: Sternberg R J, Weis K, eds. The New Psychology of L ove. New York: Yale University Press, 1989

[12]. Fisher H E, Aron A, Brown L L. Romantic love: A mammalian brain system for mate choice. Philos T Roy Soc B, 2006, 361: 2173-2186 